\title{
Flavio Munhoz Sofiati, Religião e Juventude - Os novos carismáticos
}

São Paulo, Editora ideias \& letras, 2011, 275 p.

Guénolé Labéy-Guimard

\section{(2) OpenEdition}

\section{Journals}

Édition électronique

URL : http://journals.openedition.org/assr/26561

DOI : 10.4000 /assr.26561

ISSN : $1777-5825$

Éditeur

Éditions de l'EHESS

Édition imprimée

Date de publication : 31 décembre 2014

Pagination : 291

ISBN : 978-2-7132-2467-6

ISSN : 0335-5985

Référence électronique

Guénolé Labéy-Guimard, "Flavio Munhoz Sofiati, Religião e Juventude - Os novos carismáticos »,

Archives de sciences sociales des religions [En ligne], 168|2014, mis en ligne le 21 mai 2015, consulté le 22 septembre 2020. URL : http://journals.openedition.org/assr/26561; DOI : https://doi.org/10.4000/ assr. 26561

Ce document a été généré automatiquement le 22 septembre 2020.

(c) Archives de sciences sociales des religions 


\title{
Flavio Munhoz Sofiati, Religião e Juventude - Os novos carismáticos
}

São Paulo, Editora ideias \& letras, 2011, 275 p.

\author{
Guénolé Labéy-Guimard
}

1 Le sociologue brésilien Flávio Sofiati, professeur à l'Université Fédérale de Goiás, publie un ouvrage consacré au renouveau charismatique au Brésil. Le principal terrain d'étude de cette enquête se situe à Araraquara, une ville de l'État de São Paulo, dans une communauté appelée Canção Nova (Chanson Nouvelle) qui possède dans cette ville une importante structure et anime de nombreux groupes d'oraisons. Il s'agit ici de groupes charismatiques catholiques, c'est-à-dire d'un courant religieux au sein de l'Église catholique. La problématique consiste à comprendre pourquoi des jeunes se tournent vers ces nouvelles communautés religieuses. Par quels moyens ces groupes attirent-ils à eux de nombreux jeunes Brésiliens?

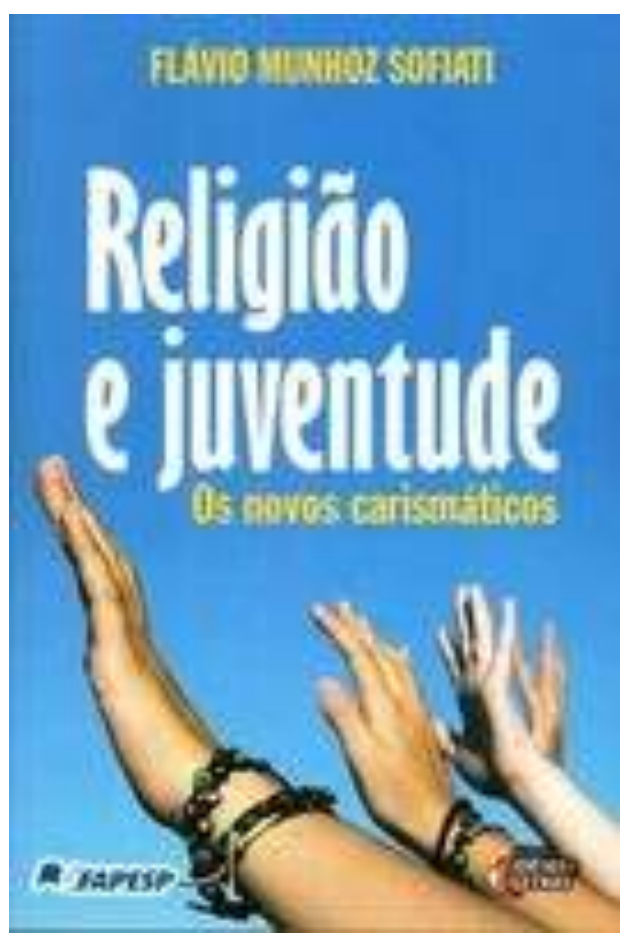

2 L'hypothèse développée pour répondre à cette question réside, d'une part, dans l'utilisation de moyens de communication de masse (internet, TV , CD) donnant une large place à la dimension émotionnelle (chants, exorcisme, guérisons, glossolalie); et d'autre part, dans la fragilisation des structures sociales et politiques qui entraînerait un retour vers l'univers religieux. L'auteur emploie même l'expression de « refuge » (p. 18) offert par la sphère religieuse face au chômage, à la précarité et aux désillusions du monde politique. 
3 Le livre est organisé en six chapitres regroupés en trois axes. F. Sofiati dresse le portrait de la jeunesse brésilienne catholique dans un premier temps, il décrit dans un deuxième temps le contexte religieux brésilien avant de revenir dans un troisième et dernier axe sur la jeunesse charismatique brésilienne.

4 La première partie, intitulée "Sociologie de la jeunesse catholique ", montre que les institutions religieuses jouent un rôle important dans la socialisation de la jeunesse brésilienne, notamment au regard de l'implication politique qui est très faible pour les générations actuelles. Toutefois, au regard des statistiques présentées (p. 44), ils ne sont que $4 \%$ à être engagés dans une organisation religieuse contre $11 \%$ dans des institutions sportives ou artistiques, mais le chiffre clé reste celui de $85 \%$ de jeunes Brésiliens n'ayant aucune forme d'engagement quelconque. Flávio Sofiati cherche ensuite à comprendre pourquoi les jeunes catholiques sont passés d'un engagement à visée politique et citoyenne (théologie de la libération) à un engagement plus personnel, introspectif et organisé en communauté. Selon l'auteur, c'est justement l'aspect communautaire qui attire les jeunes et favorise leur intégration au sein des groupes catholiques charismatiques. Le mouvement Canção Nova parvient à réunir des groupes au sein de séances d'oraisons régulières tout en organisant des événements plus festifs visant un public plus large. Autre élément clé, l'existence de leaders charismatiques donne une force et une unité à chaque groupe d'oraison. Le succès de ces groupes religieux provient d'une autorité charismatique (Max Weber) reconnue par les participants et qui assure le dynamisme des groupes étudiés dans cet ouvrage.

La deuxième partie du livre traite du contexte religieux brésilien, plus précisément de son évolution depuis 1970. Ce nouveau contexte religieux repose pour l'auteur sur trois caractéristiques. La première est la pluralisation de la scène religieuse avec l'apparition des évangéliques (15\% des Brésiliens) bien que les catholiques demeurent largement majoritaires ( $75 \%$ des Brésiliens). La deuxième caractéristique est que la rationalisation du monde (administrations, technologies, etc.) ne touche pas - ou peu - la sphère religieuse au Brésil, qui conserve son enchantement propre. Enfin, l'une des principales évolutions concerne la structure même de la religion qui est devenue un « marché ", où règne une concurrence forte découlant de la fin du monopole de l'Église catholique. L'auteur apporte une analyse pénétrante pour expliquer l'avènement de ce nouveau contexte, qui est lié, selon lui, à l'accélération du processus d'urbanisation à partir des années 1970 qui a favorisé l'avènement d'un pluralisme religieux ainsi que l'apparition de nouveaux courants religieux venus de l'étranger. Notons qu'il existe, à l'image des catholiques charismatiques, une nouvelle offre à l'intérieur même de l'Église catholique. Flávio Sofiati reprend la typologie de Jão Batista Libanio qui décrit quatre courants au sein de l'Église catholique: a) l'Église institutionnelle (importance du clergé), b) les charismatiques (individualiste, émotion), c) l'Église de prédication (importance des prêches et de la catéchèse), d) l'Église de la théologie de la libération (option préférentielle pour les pauvres). La rénovation charismatique catholique suit la tendance des mouvements protestants évangéliques et pentecôtistes axés sur une expérience personnelle et intime de la relation avec Dieu. Le mouvement de rénovation catholique charismatique apparaît au Brésil dans les années 1970 et se développe en récupérant des fidèles peu pratiquants qui avaient délaissé les églises traditionnelles. Selon l'auteur, la crise sociale et l'absence de vision du futur amènent les jeunes vers ce nouveau mouvement religieux, celui-ci permettant un enchantement du monde produit par une approche plus émotionnelle, individualiste et avec une efficacité 
rapide. Une triple finalité oriente ainsi, selon l'auteur, la rénovation charismatique catholique : a) chercher un sens à sa vie, b) trouver un chemin pour dépasser les obstacles sociaux et personnels c) développer un vecteur d'identité.

6 La troisième partie du livre, intitulée " La jeunesse charismatique au Brésil », s'attache à décrire le fonctionnement et les activités des groupes charismatiques. Outre les groupes d'oraison Novo Pentocostes de la ville d'Araraquara, l'auteur va ici détailler le fonctionnement du mouvement Canção Nova et son application théologique et morale. Canção Nova recrute beaucoup dans les universités et parmi les jeunes professionnels, développant ses universités de la Rénovation au sein de certaines universités publiques. Le but est de pouvoir améliorer la société via les (futures) élites. Le pouvoir charismatique des leaders réside non seulement dans l'organisation de réunions, mais aussi dans la mise en place de communautés (louanges, rencontres, chansons, médias) par-delà l'appartenance paroissiale. L'évangélisation se base sur la socialisation au sein de ces communautés. Canção Nova est l'une de ces communautés charismatiques, fondée en 1978 par Monseigneur Jonas Abib avec un groupe de douze fidèles. Elle compte aujourd'hui plus de 600 membres et possède des locaux à Cachoiera-Paulista pour organiser des événements, éditer des médias (TV, radio, internet, livres). Dunga, chanteur et présentateur TV de Canção Nova, y organise des semaines PHN (Por Hoje Não). Le PHN est une doctrine théologique qui consiste à combattre le mal quotidiennement, à contrôler ses relations sexuelles, à ne pas avoir de relations avant le mariage et à rejeter les drogues. En 2009, près de 180000 jeunes ont participé aux deux semaines d'activités proposées à Cachoiera-Paulista. Parmi les activités, en dehors des groupes d'oraison, des louanges et des enseignements, nous trouvons aussi le « Bar de Jésus » ou la "Christothèque ». La musique et la fête jouent un rôle important dans la socialisation des fidèles. Néanmoins, elles sont toujours rattachées à des éléments religieux et proscrivent les drogues et les comportements déviants. Tous les lieux de camping et d'hébergements de la ville sont pleins lorsque la communauté organise cet événement annuel. La spiritualité des charismatiques découle des cinq éléments révélés à Medugorje par la Vierge: l'oraison du rosaire, la communion eucharistique quotidienne, la lecture de la Bible, le jeûne et la confession devant un membre sacerdotal. Un dualisme se construit entre la morale du groupe et la morale du monde amenant les catholiques charismatiques à s'éloigner des sphères séculières. Le but des charismatiques est de faire la rencontre personnelle de Dieu, débouchant ainsi sur un " second baptême ». Un chemin vers la sainteté va ainsi se mettre en place autour d'une "option préférentielle pour la chasteté » et d'une cure contre les excès de la société (sexe, drogue, crime). Les piliers de ce cheminement sont l'oraison individuelle et collective. L'aspect émotionnel prend la primauté par rapport au dogme ou à la filiation familiale. Dans cette perspective, le groupe d'oraison, Novo Pentecostes s'organise autour d'un temps d'oraison collectif hebdomadaire, un temps personnel et des moments de cure. Chaque groupe est géré par un jeune ayant un fort charisme, pouvant aller jusqu'à développer des dons de guérisseurs, comme Claudinei dans le groupe Novo Pentecostes d'Araraquara. Toutefois, l'auteur insiste sur le caractère provisoire du passage dans un groupe charismatique, d'une part parce qu'il s'agit souvent d'une période limitée dans le temps; et d'autre part en fonction de la très grande rotation des participants. Qui plus est, des tensions entre l'Église paroissiale et les groupes charismatiques sont apparues. Cette partie se conclut par une comparaison avec la France. Les groupes charismatiques sont semblables dans leur organisation, si ce n'est qu'il n'existe pas en France de lieu équivalent à celui de Canção Nova basé à Cachoiera Paulista. 
7 Ce livre fait preuve d'une approche toute à la fois documentée par une solide connaissance du terrain d'étude, et par la volonté de proposer un cadre théorique pour comprendre le succès de ce nouveau mouvement religieux. L'absence de portrait de jeunes charismatiques est l'une des critiques que l'on peut adresser à l'ouvrage, notamment pour un lecteur peu habitué à ces nouveaux mouvements. 